\title{
VIH/SIDA Y REDUCCIÓN DE DAÑOS ENTRE USUARIOS DE DROGAS INYECTABLES
}

\author{
RAÚL SORIANO
}

Trabajador Social. Médicos del Mundo. Valencia.

MARISA DORADO

Médica. Médicos del Mundo. Valencia.

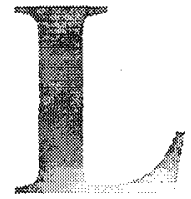

a infección por VIH/SIDA representa un problema de salud pública con una importante repercusión en el contexto de nuestra sociedad actual. El escenario en el que nos encontramos se ha transformado radical y desigualmente durante los últimos años. Mientras en los países más desarrollados los nuevos fármacos han favorecido una tendencia a la cronificación de la infección, en otras latitudes la pandemia queda fuera de todo control. En la área del África subsahariana el avance del virus y de la enfermedad continúa incesante y los medios técnicos invertidos para hacerle frente son desproporcionadamente minúsculos.

En España el patrón de transmisión del virus ha sufrido ciertas variaciones a lo largo del tiempo, pero puede afirmarse que en una gran parte de los casos conocidos, la infección se encuentra relacionada de algún modo con el consumo de drogas por vía parenteral y con las prácticas de estos consumidores, lo que ha promovido la implementación de políticas y recursos encaminados a trabajar la prevención secundaria y terciaria con dicha población.

En el presente texto se recogen algunas orientaciones básicas sobre la infección por VIH/SIDA, y sobre los trastornos adictivos producidos por la dependencia a opiáceos, otras drogas inyectables y su terapéutica. Se explica cómo se relacionan ciertas prácticas de consumo de sustancias con la transmisión del VIH. Y se describe el desarrollo que las políticas de «reducción de daños asociados al consumo» están viviendo en la actualidad, reconociendo sus principales estrategias de intervención desde los Servicios Sociales Especializados.

\section{INTRODUCCIÓN: LA INFECCIÓN POR VIH/SIDA HOY}

El SIDA es una enfermedad que produce una desorganización del sistema inmunológico. Su agente causal es el virus de la inmunode- 
ficiencia Humana (VIH), que pertenece a la familia de los retrovirus y provoca una infección de carácter lento. La persona afectada puede convivir durante un largo periodo de años con la infección sin presentar síntoma alguno. Durante este periodo es cuando se le denomina persona seropositiva, portadora de anticuerpos del VIH, o VIH+. Cuando con el paso del tiempo el virus causa una afectación intensa de las defensas del organismo, éste pierde la capacidad para evitar el desarrollo de infecciones y de ciertos cánceres. Tras el diagnóstico de determinados procesos y afectaciones, la persona llega a la fase de la infección en la que pasa a considerarse enferma de SIDA.

El VIH está presente en varios fluidos del organismo, aunque solo en algunos adquiere la concentración suficiente como para poder transmitirse e infectar, éstos son: la sangre, el semen, los flujos vaginales y la leche materna. Para invadir un organismo el virus necesita acceder al torrente sanguíneo. Las prácticas de riesgo para contraer la infección pueden agruparse en varias categorías. Generalmente nos referimos a éstas como las vías de transmisión, y pueden concretarse en las siguientes: sanguínea, sexual y vertical o materno-infantil.

La transmisión sanguínea se produce básicamente al compartir agujas y objetos punzantes o cortantes que trasladan sangre infectada de una persona a otra. La transmisión sexual tiene lugar cuando fluidos eyaculatorios o vaginales infectados encuentran una puerta de entrada en puntos vulnerables de las mucosas genitales, rectal o bucal. En el caso de la transmisión de madre a hijo, la infección puede darse durante el embarazo, en el momento del parto o en la lactancia.

El patrón de transmisión, o predominio de unas vías sobre otras en la generación de nuevas infecciones, registra variaciones geográficas y cronológicas. Así, en países como España, Italia o Suiza, la vía que genera un mayor número de afectados es la sanguínea, concretada en el uso compartido de material de inyección entre los UDIs (usuarios de drogas inyectables). Mientras, en otras latitudes son más frecuentes los patrones de transmisión sexual y vertical.

Las autoridades sanitarias estiman que el número de personas que conviven con la infección en todo el mundo se encuentra en torno a los 33 millones. La mayor parte de ellas (más del 90\%) viven en el tercer mundo, sobretodo en el África Subsahariana y en el Sur y Sureste de Asia. España es el país europeo con un mayor número de casos. Esto puede relacionarse, entre otros factores, con el importante volumen de usuarios de drogas inyectables que han tenido y tienen prácticas de riesgo, y con la tardanza e insuficiencia en la implementación de acciones preventivas. 
La prevención de infecciones por VIH en la vía sanguínea se centra en el uso de material de inyección nuevo (o en su defecto desinfectado), y en evitar el uso compartido de útiles cortantes o punzantes sin esterilizar. En las prácticas de riesgo de carácter sexual es necesario impedir el intercambio de fluidos sexuales durante las penetraciones anal, vaginal y oral, además de en los contactos bucogenitales, utilizando adecuadamente barreras como los preservativos y los cuadrantes de latex.

Los últimos avances farmacológicos están produciendo grandes cambios en el pronóstico y en la calidad de vida de las personas que conviven con la infección. Las terapias que combinan varios fármacos atacan diferentes momentos del ciclo vital del virus, lo que produce un retraso en la evolución del proceso, aumentando su eficacia y tolerancia cuanto más precoz es su utilización (G.V., 1999).

A pesar de todo, el contraste entre la incidencia geográfica de la infección y el destino final de los recursos que se invierten para hacerle frente, resulta severamente discordante. La aparición de vacunas o medicaciones eficaces puede suponer, en su accesibilidad, un agravio comparativo de proporciones magnicidas. Planificar un acceso racional a los tratamientos es un reto para la comunidad internacional, de una magnitud tan trascendente a nivel humano y demográfico, que las autoridades sanitarias deberían tomar decisiones drásticas para evitar, que las multinacionales y los intereses del mercado, sean quienes juzguen quiénes y cuándo tienen derecho y acceso a una medicación vital (Soriano, 1998).

\section{TRASTORNOS ADICTIVOS POR DEPENDENCIA A OPIÁCEOS}

\subsection{Características del trastorno}

Con el término de «opiáceos» se conoce a las sustancias de la familia del opio, producto obtenido de un tipo de amapola, la adormidera o Papaver somniferum, que crece en diferentes latitudes de forma natural o cultivada. La sustancia se extrae mediante una incisión en las cápsulas inmaduras de la planta, produciéndose un jugo blanco viscoso que se coagula rápidamente y se transforma en una pasta de color parduzco (Sanchís y Martín, 1997). Históricamente, el opio ha sido utilizado en la medicina tradicional por sus propiedades analgésicas, somníferas o antitusivas. Durante los dos últimos siglos se han conseguido identificar numerosos derivados opiáceos (los hay naturales, sintéticos o semisintéticos). Los más populares son la morfina, la heroína, codeína, 
metadona, LAAM y buprenorfina. De algún modo, nuestro organismo también produce unas sustancias opioides endógenas que actúan sobre ciertos receptores del Sistema Nervioso Central (S.N.C.); al parecer se encuentran involucradas en la modulación del estado de ánimo, del dolor, estrés, placer...

La heroína es un derivado químico de la morfina, pero sus efectos son mucho más rápidos y potentes. Su consumo por vía intravenosa produce el llamado «flash»: sensación de placer intenso comparable al orgasmo, pero de diferente cualidad, y que dura escasos segundos. Posteriormente aparece un estado de euforia («rush»), sedación, acompañado de un cálido sonrojo de la piel, boca seca y extremidades pesadas. Durante unas pocas horas se alternan la vigilia con el adormecimiento y se turban las facultades mentales debido a la depresión del Sistema Nervioso Central (Nida, 1999; Castañeda, 1992).

El uso regular de heroína produce tolerancia a la sustancia, lo que lleva al consumidor a tomar una mayor dosis para obtener la misma intensidad o efecto. En el establecimiento de la dependencia intervienen conjuntamente diversos factores de riesgo, que varían de un sujeto a otro. Estos factores pueden tener un carácter personal (como la presencia de patologías psiquiátricas), familiar (como antecedentes de drogodependencia paternos, familias desestructuradas o pareja consumidora), comunitario (domicilio en zonas urbanas marginales, escasez de equipamientos y recursos sociales, presencia del tráfico de sustancias...), etc. El mismo consumo contribuye per se a reforzar la conducta, pues la sustancia actúa reduciendo la ansiedad y generando sensación de calma y evasión. Una vez establecida la adicción física, el organismo puede sufrir el síndrome de abstinencia si se reduce o abandona el uso de la sustancia. El síndrome de abstinencia a opiáceos se caracteriza por una serie de síntomas como lagrimeo, rinorrea, bostezos, temblores o escalofríos y sudoración, completándose con dolores musculares y de huesos, insomnio, ansiedad, diarrea, vómitos...

Al tratarse de una sustancia no controlada y sometida a todo tipo de manipulaciones irregulares, el grado de pureza (que suele ser muy bajo) puede variar según su procedencia. Si el usuario se inyecta la misma cantidad habitualmente, pero en un momento determinado obtiene una dosis de mayor pureza, puede sufrir una sobredosis, e incluso morir bajo la saturación de depresores del S.N.C. Este riesgo es menor en aquellos usuarios que consumen habitualmente por vía fumada/inhalada, lo que en el argot se conoce como «hacerse un chino» o «fumar en plata», ya que por esta vía el aprovechamiento del principio activo es más reducido. En dicho procedimiento de consumo el usuario inhala, a través de un pequeño tubo colocado en la boca, los vapores que desprende la heroína al ser calentada sobre un trozo de papel de aluminio. 
El debut del trastorno por dependencia a opiáceos integra, además de las variables orgánicas, otros componentes de carácter psicológico y social. En la instauración de la adicción psíquica intervienen ciertas respuestas características que retroalimentan la continuidad de la dependencia. El miedo al síndrome de abstinencia y el «craving» o deseo de consumir, operan como verdaderos acicates para movilizar al usuario y satisfacer esta necesidad por encima de otras que se antojarían básicas, como alimentarse o dormir. Como se describe más adelante sobre el perfil de esta población, las relaciones sociales del adicto se redefinen y aglutinan en torno a las drogas y para las drogas.

Actualmente es difícil encontrar un usuario de drogas que consuma una sola sustancia, resulta más habitual el uso simultáneo o combinado de varias de ellas. Este fenómeno se conoce como policonsumo o polidrogodependencia. Entre los dependientes a opiáceos es frecuente el uso, abuso o dependencia de cocaína, alcohol o benzodiacepinas. Cuando el preparado inyectable contiene conjuntamente la mezcla de heroína y cocaína recibe la dominación de «speed-ball». Durante 1997 la dependencia a heroína como droga principal motivó el $84.1 \%$ de las admisiones a tratamiento de todo el Estado (PND, 1999). Sin embargo, el aumento progresivo del consumo de cocaína entre los usuarios de heroína está adquiriendo un protagonismo extraordinario. Entre las personas admitidas a tratamiento por el consumo de heroína como sustancia principal durante 1998 , el 74 ' $8 \%$ manifestaban haber consumido también cocaína (PND, 2000). Es necesario mencionar que entre este colectivo el uso de cocaína se produce más frecuentemente por la vía inyectada, por lo que todas las prácticas de riesgo asociadas a dicha vía se hacen extensibles a quienes la utilizan, con independencia de la sustancia o sustancias consumidas.

\subsection{VIH/SIDA y enfermedades asociadas a la vía de consumo}

Cualquier consumo de sustancias produce una serie de efectos en el organismo que influyen directamente sobre su salud. En el mercado de las drogas ilegales éstas pasan sucesivamente por intermediarios que añaden substancias no controladas al producto antes de que éste llegue a manos del interesado. Por esta razón las consecuencias de su uso pueden llegar a ser mucho más nocivas y difíciles de prever. La vía de consumo añade un riesgo específico derivado de la manipulación del material de inyección y de las prácticas de autoadministración. Los procesos por los que se consiguen introducir las drogas en el organismo pueden ser muy variados, generalmente se distinguen las siguientes vías de administración: inyectada (también conocida como intravenosa o parenteral), fumada, inhalada (estas dos llamadas también vía pulmonar), 
esnifada (o intranasal), cutánea y oral. Además, diferentes mucosas pueden actuar como vía de acceso para sustancias, como ocurre con las vías rectal, vaginal o sublingual. En nuestro contexto, las vías más habituales para el consumo de heroína son la inyectada y la fumada/ inhalada. Las vías de administración de cocaína presentan más variedad, en el ámbito de los usuarios de drogas inyectables (UDIs) prevalece la vía parenteral y el consumo «en base», para el resto de la población es más común el uso esnifado.

Algunas vías de administración resultan más agresivas y traumáticas que otras. La intravenosa es una de las que presenta más riesgos, tanto por las lesiones e infecciones derivadas de una manipulación inadecuada del material de inyección, como por la transmisión de enfermedades entre individuos que comparten el instrumental durante el ritual de consumo. El riesgo no sólo se encuentra en usar la misma jeringuilla para varios individuos; por ejemplo, preparar la «mezcla» compartiendo un mismo recipiente (cuchara, tapón, bote de bebida...) es también un hábito extendido en esta población. No todos los usuarios de drogas inyectables (UDIs) tienen suficientes conocimientos ni destreza para proceder a inyectarse con un mínimo de garantías. La falta de información y de habilidades puede dar lugar a procesos como los abcesos.

El aprovechamiento del principio activo de una sustancia y el tiempo necesario para percibir sus efectos difiere de unas vías a otras. Es en el caso de la inyectada donde el usuario obtiene un mayor rendimiento de su dosis y donde percibe su actuación más directa y rápidamente. Por este motivo, para alcanzar un determinado nivel de efectos, la cantidad de sustancia necesaria es sensiblemente menor en el caso de utilizar la vía parenteral frente al uso de la vía fumada/inhalada.

Sobre la elección de la vía de consumo operan multitud de circunstancias. Los usos y procesos de autoadministración de las drogas pueden modificarse a lo largo del tiempo, están condicionados por modas locales, variaciones en la accesibilidad física a las sustancias, tipo de sustancia comercializada, variaciones del grado de pureza, disponibilidad de útiles de consumo, creencias... Además entran en colación factores fisiológicos (por ejemplo, tener las venas cangrosadas) y psicológicos individuales (miedo a las agujas). Algunos tipos de heroína son solamente apropiados para el consumo fumado/inhalado. Esta vía es de más reciente incorporación a los usos de la población heroinómana, aunque se estima que se ha popularizado de un modo importante durante los últimos años. Entre las personas heroinómanas admitidas a su primer tratamiento en España durante 1997, el 23'8\% había utilizado la vía parenteral y el 67'2\% la pulmonar, mientras que entre los usuarios que ya habían sido tratados previamente estos porcentajes fueron res- 
pectivamente de un 34 ' $8 \%$ y de un $57^{\prime} 8 \%$ (PND, 1999). Compartir el tubo que se utiliza para «fumar plata» conlleva riesgos para la transmisión de algunas enfermedades.

En cualquier caso, es el uso incorrecto de la vía inyectada lo que comporta mayores daños para esta población, al tratarse de la principal fuente de transmisión del VIH y de la hepatitis vírica. Habiendo ya descrito el primero en un apartado anterior, nos ocupamos ahora de la segunda. El término hepatitis se aplica a aquellos procesos que afectan al hígado produciendo, entre otros síntomas, su inflamación. Existen muchos tipos de hepatitis, pero las más frecuentes son las producidas por unos virus que se identifican con letras (A, B, C, D, E, G). Cuando dichos virus consiguen introducirse en el organismo, se dirigen al hígado penetrando en las células, a las que infectan y en cuyo interior se reproducen. Las hepatitis pueden cursar como un proceso agudo, o bien crónico. Muchas personas padecen una hepatitis asintomática y descubren su infección a través de chequeos rutinarios. La identificación del tipo de hepatitis que sufre un sujeto se realiza mediante una analítica de sangre, que determina cuáles son las partículas víricas que circulan por ella o bien los anticuerpos que el organismo ha generado para combatirlas (Schering-Plough, S.A., 1998).

\subsection{Perfil bio-psico-social de los UDIs}

El perfil bio-psico-social del usuario de drogas resulta determinante para valorar la indicación de una intervención y para decidir su inclusión en un programa determinado. Entre los aspectos objeto de análisis pueden encontrarse: los antecedentes toxicológicos, la trayectoria terapéutica, el historial clínico, el diagnóstico de trastornos asociados, las relaciones con las redes sociales primarias, etc. Además se estiman aspectos complementarios pero tan influyentes como la motivación del usuario por un tipo concreto de terapéutica, la presencia de un embarazo en curso, o las listas de espera para acceder a los dispositivos técnicos.

Si bien por la heterogeneidad de la población no resulta sencillo acreditar datos precisos sobre su perfil medio, pueden anotarse algunos comentarios como referencia. Las estimaciones sobre el sexo de las personas adictas a opiáceos en España reflejan una proporción entre 1/4 y $1 / 5$ de mujeres respecto a hombres, con ligeras variaciones de unas Comunidades Autónomas a otras. La edad media de los usuarios ronda los 33 años, y se aprecia un envejecimiento progresivo de la población. Como característica más uniformemente destacable desde una perspectiva sanitaria puede considerarse la alta presencia de enfermedades asociadas o derivadas de sus prácticas y estilo de vida, como el 
VIH/SIDA, las hepatitis víricas o la tuberculosis.

Desde la vertiente psicológica, la población adicta a opiáceos presenta una elevada prevalencia de Trastornos de Personalidad. De éstos, los más frecuentes son el Trastorno de Personalidad Antisocial y el Límite, seguidos por el de Evitación y el Paranoide (Gutiérrez, E. et al., 1998; E.T. U.C.A. Cruz Roja Valencia, 1998). La existencia de un tipo concreto de trastorno puede favorecer un deterioro de su situación. Algunos estudios relacionan la personalidad antisocial con mayores probabilidades de contraer la infección por VIH entre usuarios de drogas por vía parenteral (Brooner et al., 1993).

Para interpretar y comprender la naturaleza del fenómeno es necesario incorporar al análisis la perspectiva que aporta el estudio de la Patología Dual. Con este término se hace referencia a la coexistencia simultánea de patología psiquiátrica y trastornos por abuso y dependencia a sustancias en un mismo sujeto. La convivencia de estos trastornos produce una sinergia que repercute sobre el debut y el establecimiento de ambos. El paciente con Patología Dual presenta peor pronóstico al tratarse de dos patologías crónicas y recidivantes (que cursa con periodos de remisión y de agudización). Si además se trata de una persona enferma de SIDA en fases avanzadas puede llegar a padecer, entre otras posibilidades, ciertos tipos de demencia asociada al síndrome, lo que termina por conferir al cuadro unas perspectivas nada alentadoras.

Por lo que se refiere a los aspectos sociales y sus características predominantes en esta población, puede entenderse que su itinerario de marginalización discurre paralelo a la trayectoria de su proceso adictivo. Mayor severidad de la adicción y del deterioro físico y psicológico se corresponden con mayores dificultades para desinhibirse de su rutina de consumo, sobre la que giran la mayor parte de sus interacciones sociales habituales. El reloj biológico de los consumidores de drogas inyectables no está sincronizado con los usos y sistemas de normas que rigen a la población normalizada (Soriano, 2001).

Los primeros encuentros con la sustancia (lo que se conoce como «luna de miel») suelen ser periodos donde el usuario puede tratar de ocultar su consumo, y en los que le es posible mantener vínculos familiares y sociales. Conforme se instaura la dependencia resulta mucho más difícil compatibilizar ambas realidades. Progresivamente una parte de los consumidores deja de transitar por los circuitos normalizados, iniciando una espiral endogámica donde todo interacciona alrededor de la sustancia. Cuando la edad de inicio del consumo es temprana, el truncamiento del proyecto vital llega a ser más considerable. Estudios recientes del Observatorio Español Sobre Drogas aportan datos como que entre los drogodependientes en los que la heroína es la «droga 
principal» de admisión a tratamiento, solamente el 14'1 ha completado estudios de B.U.P. o superiores (PND, 1999).

Por lo general, los usuarios cronificados en el consumo de drogas inyectables presentan un bajo nivel educativo, escasa o nula experiencia laboral reciente y, lógicamente, altas tasas de desocupación. Las relaciones familiares tienden a ser conflictivas o inexistentes. Si hay hijos menores es frecuente la institucionalización o la asunción del cuidado y educación por parte de los abuelos. Una parte de los adictos son transeúntes o viven en casas «ocupadas». La necesidad de obtener importantes recursos económicos para mantener el consumo se traduce habitualmente en el ejercicio de la mendicidad, la prostitución, el tráfico de menudeo de sustancias o la comisión de delitos, entre otras alternativas. El tener causas pendientes con la justicia o haber ingresado en prisión son otra expresión corriente de sus circunstancias personales.

Una parte de esta población debido a su alto deterioro general presenta un mal pronóstico. Hay usuarios severamente deteriorados, de salud precaria y con tantas secuelas de su proceso, que con toda probabilidad nunca llegarán a tener acceso a un trabajo normalizado y a una autonomía económica. Sus posibilidades de integración sociolaboral son bien remotas, escasas aun en el supuesto que evolucionaran favorablemente de su drogodependencia. Si continúan sobreviviendo será necesario prever nuevos conceptos de abordaje superadores de la perspectiva de reducción del daño y que aporten alternativas de convivencia y cuidado sostenibles a medio/largo plazo.

\section{LA REDUCCIÓN DE DAÑOS COMO MARCO DE INTER- VENCIÓN}

\subsection{La infección por VIH/SIDA como impulsora de las políticas} de reducción de daños

La evolución de la oferta terapéutica para el abordaje de las adicciones a la heroína y a la cocaína ha conllevado, desde finales de los años setenta hasta la actualidad, la aparición gradual de diversas alternativas a menudo antagónicas en sus postulados teóricos y metodológicos. Si tuviéramos que trazar un hilo conductor que relacionara cronológica y argumentalmente estas trayectorias terapéuticas, pronto advertiríamos una tendencia creciente por adaptar los objetivos del tratamiento a las posibilidades reales de los pacientes (Soriano, 2001).

Durante las primeras etapas históricas del abordaje terapéutico de 
los trastornos derivados del uso de drogas era frecuente que el fracaso en los tratamientos se achacara a la «falta de motivación» del usuario. El «desmotivado» quedaba así en una posición poco favorable para validar su consideración de sujeto a «tratar». En nuestros días, por el contrario, no se entendería que un profesional dejara de atender a una menor anoréxica o a una persona diagnosticada de «depresión mayor» esgrimiendo como argumento una falta de motivación. Es más, en el caso de los enfermos de anorexia ha prosperado una legislación que promueve incluso el ingreso hospitalario por orden judicial aun en contra de la voluntad del paciente. Se trata así de preservar su salud frente a un deterioro inminente, al estimarse que la enfermedad limita esa capacidad para el autocuidado. Claro que la construcción social sobre la anorexia tiende a victimizar al enfermo, al contrario que ocurre con el drogodependiente, fácilmente satanizado.

Pues bien, en el caso que nos ocupa, la «exigencia» ha sido el marco que ha modulado durante años las relaciones profesional-paciente. Sólo el volumen de fracasos y la entrada en escena de patologías asociadas al consumo de ineludible acomisión, han empujado verdaderamente unos cambios de envergadura en las políticas socio-sanitarias del sector. Desde la aparición del VIH/SIDA, el interés por preservar la vida del sujeto ha impulsado, por ejemplo, la apertura de los criterios de inclusión en los programas de mantenimiento con Metadona. A menudo evitar conductas de riesgo para la infección o reinfección por VIH se antepone a los objetivos orientados a la abstinencia. Desde una perspectiva deontológica, no puede resultar aceptable abandonar a su suerte a aquellos usuarios de drogas cuyo trastorno y/o limitaciones personales le dificultan o impiden operar cambios en sus conductas de riesgo.

La pandemia del VIH/SIDA ha sido, por su dimensión como fenómeno de salud pública, el factor que ha ejercido una mayor influencia sobre la implementación de políticas y estrategias destinadas a aquellos usuarios que no pueden o no quieren abandonar el consumo de drogas. Bajo la premisa de la accesibilidad, se ha reconocido como un derecho una necesidad de atención, la de un público que hasta el momento no encontraba cabida en el circuito asistencial (Soriano, 2001).

\subsection{Reducción de daños - Fundamentos teóricos}

La reducción de daños, también llamada reducción o disminución del riesgo, se trata de una actuación dirigida a aquellos sujetos más deteriorados sanitaria y socialmente, y que básicamente se concreta en aquellas «acciones individuales y colectivas, de carácter social o sanitario, tendentes a disminuir los efectos negativos asociados 


\section{al consumo de drogas".}

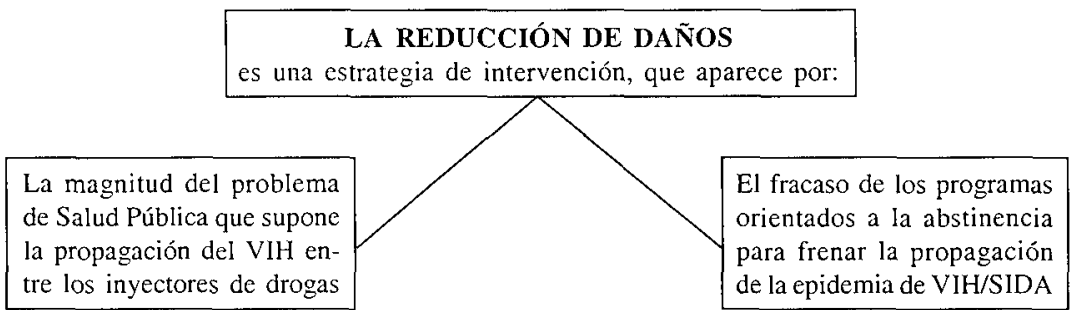

Los objetivos de la reducción de daños se basan en una dinámica jerárquica, que se establece de forma diferente según la meta propuesta. La meta más conocida es la aprobada por el Consejo Consultivo sobre el Abuso de Drogas del gobierno británico (1988-1989), y que se refiere a la implementación de estrategias para reducir la transmisión de la infección por el VIH entre y desde los inyectores de drogas. La escala de sus referencias se apoya en la siguiente secuencia:

No consumir drogas $\rightarrow$ si se consume, no hacerlo por vía intravenosa $\rightarrow$ si se hace por vía intravenosa, utilizar una jeringuilla estéril una sola vez. $\rightarrow$ si se reutiliza la jeringuilla límpiarla con lejía, etc.

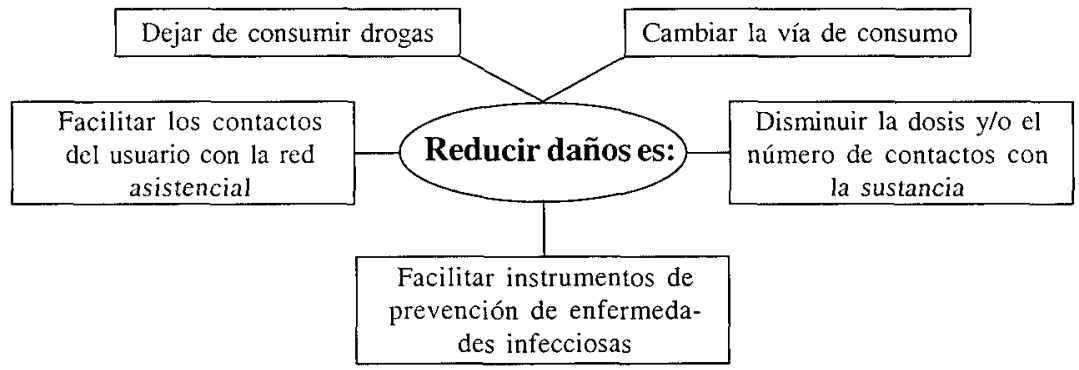

Es importante desarrollar conceptos precisos porque esto permite medir y evaluar la efectividad de las intervenciones de reducción de daños. Así pues se define como:

Riesgo: la probabilidad que tiene la conducta de "consumir drogas" de causar diferentes consecuencias.

Daño y beneficio: son dos términos complementarios, describen si una consecuencia concreta es vista como negativa o positiva.

Las políticas e intervenciones que actúan sobre los daños y beneficios pueden vertebrarse desde diferentes niveles y perspectivas, que se 
traducen en una amplia graduación de objetivos. La conceptualización de la reducción del daño (R.D.) se produce a finales de la década de los 80. Para organizar la planificación de estrategias Newcome realiza en 1989 una propuesta que se traduce en el siguiente cuadro:

\begin{tabular}{|c|c|c|c|}
\hline NIVEL & \multicolumn{3}{|c|}{ TIPO } \\
\hline & Salud & Social & Económico \\
\hline Individuo & & & \\
\hline Comunidad & & & \\
\hline Sociedad & & & \\
\hline
\end{tabular}

Ya a principios de los años 90 Erst Buning, propone el siguiente modificado:

\begin{tabular}{|c|c|c|c|}
\hline \multirow[t]{2}{*}{ NIVEL } & \multicolumn{3}{|c|}{ TIPO } \\
\hline & Salud & Social & Económico \\
\hline Individuo & $\begin{array}{c}\text { SIDA } \\
\text { Tuberculosis } \\
\text { Hepatitis }\end{array}$ & $\begin{array}{c}\text { Relaciones } \\
\text { Encarcelamientos } \\
\text { Marginación }\end{array}$ & $\begin{array}{l}\text { Pérdida de } \\
\text { productividad }\end{array}$ \\
\hline Sociedad & Enfermedades & $\begin{array}{c}\text { Crímenes } \\
\text { Violencia } \\
\text { Inseguridad ciudadana }\end{array}$ & $\begin{array}{l}\text { Aumento de gastos } \\
\text { por: tratamientos, } \\
\text { ingresos cn prisión, } \\
\text { medidas policialcs... }\end{array}$ \\
\hline
\end{tabular}

- La dimensión tipo daño/beneficio para la salud incluye el alcance y el tipo de trastorno, estado físico, lesiones, salud mental etc.

- La dimensión tipo daño/beneficio social incluye el alcance y el tipo de agresión/filiación, orden/desorden público, grupo de conflicto y cohesión e integración /marginación.

- La dimensión tipo daño/beneficio económico se refiere al alcance y clase de variables financieras, incluyendo deudas, delito y economía nacional.

- La dimensión tipo daño/beneficio individual se refiere a las consecuencias para el usuario de drogas.

- La dimensión tipo daño/beneficio sociedad se refiere a los efectos sobre estructuras y organizaciones sociales (por ejemplo, servicios de salud, sistema judicial penal, libertades civiles, cultura, economía).

- La dimensión tipo daño/beneficio comunitario se refiere a las consecuencias para la familia, amigos vecinos y/o compañeros del adicto (no reflejada en el modificado de Erst Buning). 
En definitiva, las respuestas de Salud Publica deben situar sus acciones en relación con las realidades de los individuos y de la comunidad desde actividades sociales, sanitarias y políticas. En estos tres niveles se incluyen y se solapan aspectos tales como los estilos de vida individuales, la oferta de los servicios asistenciales, las normas de grupo, el entorno social y los aspectos políticos y legislativos. Para garantizar la eficacia de las estrategias de reducción de daños asociados al consumo inyectado de drogas, éstas deben basarse en tres premisas básicas:

1. Aceptar que el uso más seguro de drogas es posible ante la evidencia de que no todos los usuarios de drogas vía parenteral están en condiciones de realizar tratamientos orientados a la abstinencia y que muchos de los que consumen no se acercan ni contactan con los servicios socio-sanitarios existentes.

2. Reconocer la existencia de distintos subgrupos de inyectores con diferentes necesidades, a los que hay que ofrecer soluciones múltiples y complementarias. Reconocer al consumidor como un sujeto racional capaz de elegir individualmente, con la debida información, entre distintas opciones para reducir los daños asociados al consumo de drogas, asumiendo que esta elección puede cambiar a lo largo del tiempo.

3. Reconocer la influencia de las situaciones de marginación y estigmatización asociadas al consumo de drogas como fuentes importantes de daños, distintas al consumo en sí mismo. Por ello, desde esta perspectiva, es preciso poner de manifiesto la necesidad de realizar simultáneamente esfuerzos que permitan reconocer y defender los Derechos Humanos de los usuarios de drogas no legalizadas.

\subsection{Las primeras experiencias}

La reducción de daños no es un concepto nuevo, porque los objetivos de estas intervenciones son los propios de la Salud Pública, orientados hacia la prevención y promoción de la salud (por ejemplo, la educación sanitaria para los diabéticos, los programas de infancia sana, los programas de vacunación de hepatitis B, etc.). Sí se puede considerar como estrategia novedosa, en cambio, dentro del área de drogodependencias, donde hasta no hace demasiado tiempo la actividad se orientaba exclusivamente hacia la abstinencia absoluta, y que dejaba fuera del sistema de atención a aquellos usuarios más marginales. En los primeros momentos, la construcción social del fenómeno de las drogodependencias se transcribía en el rechazo y la estigmatización sobre todo lo que rodeaba al consumo y a los consumidores de drogas ilegales. Al 
tratarse de sustancias de uso penalizado, los usuarios de drogas se relacionaban con el resto de la sociedad desde la clandestinidad y la marginalidad, provocando el alejamiento y exclusión de los servicios asistenciales, y en definitiva una mayor vulnerabilidad social y sanitaria.

En este contexto aparece a mediados de los años 80 el SIDA, la gran pandemia del siglo XX. La magnitud del problema de salud pública que supone la propagación del VIH entre los UDIs (España presenta las tasas de incidencia de SIDA más alta de la Unión Europea desde 1990), así como la percepción del fracaso de las políticas de actuación adoptadas anteriormente, constituyeron razones importantes para replantear las aproximaciones al fenómeno y provocar un cambio de ideas y discursos.

Durante los años 80 , Suiza desarrolló diferentes estrategias en el ámbito de la atención en drogodependencias, muchas de ellas canalizadas e impulsadas desde el «trabajo de campo». La creación de los «parques» de Zurich y Berna permitieron poner en evidencia la magnitud del problema, ante lo cual el gobierno Suizo decidió apoyar las iniciativas solicitadas por los profesionales y no cerrar los ojos ante la realidad que se estaba constatando. Los programas de intercambio de jeringuillas, las salas de inyección, la atención socio-sanitaria a las poblaciones más marginales y una amplia oferta de tratamientos de mantenimiento con metadona fueron las principales iniciativas que completaban la oferta de acciones orientadas a la abstinencia. Dentro de esta evolución, se llega a un punto en que se plantea la incorporación de los tratamientos con heroína como una alternativa más. Este programa se puso en marcha en 1993 como ensayo clínico en diferentes ciudades (Berna, Zurich, Basilea y Ginebra). Dichas intervenciones se basaban en la experiencia de Liverpool y Halton, en Inglaterra, donde habían comenzado ya en 1968. En Holanda, desde 1981 se estaba distribuyendo agujas limpias, para prevenir la transmisión de la Hepatitis y en 1984 aparecen los primeros programas de intercambio de jeringuillas.

En España, a pesar de liderar el primer puesto en casos de SIDA de la Unión Europea y el primer puesto mundial de transmisión del virus por vía parenteral, la mayor parte de los programas de reducción de daños aparecen 10 años más tarde (1990) que en algunos de nuestros vecinos europeos, llegan con retraso y de forma poco contundente. Las principales intervenciones en $\mathrm{RD}$ son los Programas de Intercambio de Jeringuillas (PIJ) y los Programas de Mantenimiento con Metadona (PMM). Así, los primeros programas móviles de intercambio de jeringuillas son implementados por MÉDICOS DEL MUNDO, comienzan en Madrid en 1992, y se incorporan Valencia y Sevilla en 1994. 


\section{INTERVENCIONES DE REDUCCIÓN DE DAÑOS}

\subsection{Programas de mantenimiento con Metadona (PMM)}

La Metadona es un derivado sintético del opio que, entre otros usos, se prescribe para tratar trastornos adictivos por dependencia a heroína. Administrada en una dosis estable, por vía oral y a diario, forma una reserva en el organismo que mantiene ocupados los receptores opiáceos y evita el síndrome de abstinencia. Aunque esta sustancia puede utilizarse en procesos de desintoxicación, el uso más extendido se da en programas de mantenimiento, donde la duración es indeterminada, y depende directamente de la evolución del paciente. A diferencia de otros opiáceos, como la heroína y la morfina, cuya vida media en el organismo es de 4 a 6 horas, los efectos de una dosis equivalente de metadona alcanzan una media de 24 a 36 horas. Esta particularidad permite el establecimiento pautado de un programa de «sustitutivos», donde se promueve evitar el consumo incontrolado de una sustancia adulterada e ilegal, reemplazándolo por un fármaco prescrito y regulado por un Equipo Terapéutico profesional, modificando las prácticas de riesgo y el circuito de efectos bio-psico-sociales negativos consecuencia del consumo anterior. Al mismo tiempo se trata de una sustancia farmacológicamente segura, que no genera ninguna disfunción orgánica y que normaliza las funciones alteradas por el consumo.

Tanto la metodología como los objetivos de un PMM pueden ser muy variados, pero generalmente se centran en la transformación de las conductas de dependencia a opiáceos, permitiendo un control sanitario, y mejorando su salud, esperanza y calidad de vida. Se incide sobre las relaciones familiares y sociales del paciente, y procuran la reducción de la actividad delictiva. Con la llegada de la pandemia del VIH/SIDA la orientación de muchos programas añadió a los objetivos de rehabilitación otros dirigidos a disminuir los riesgos asociados al consumo (Llorens y Fernández, 1999). Uno de los grandes pilares de estas intervenciones ha sido la capacidad para retener a los pacientes en tratamiento. Diversos estudios independientes han demostrado continuamente que el estado físico y mental de los pacientes que se mantenían en tratamiento, mejoraba (Kreek, 1983).

Los tratamientos con metadona en la dependencia a opiáceos están ampliamente aceptados e instaurados desde hace décadas en los países de la Unión Europea. En líneas generales España presenta una evolución práctica sobre este tipo de intervenciones comparable con otros Estados de su entorno, con un ritmo de integración más lento que en algunos países (Reino Unido, Holanda, Suiza o Alemania, por ejemplo), pero contemporánea a otros (como Francia, Italia, Bélgica...) 
(Hernández y Giner, 1999). En la actualidad cerca de 60.000 personas se encuentran incluidas en esos programas en el conjunto del Estado. Nunca antes una intervención en drogodependencias había vivido una demanda y un crecimiento tan espectacular.

Ahora bien, este basto crecimiento en la accesibilidad al tratamiento puede llevar a engaños, pues los recursos destinados a materializar el desarrollo práctico de los programas son a todas luces limitados, y en la mayor parte de los casos se pone más el acento en la dispensación del opiáceo que en los apoyos interdisciplinares bio-psico-sociales que constituirían el verdadero tratamiento. Sin dichos apoyos el programa terapéutico se merma tremendamente, al tiempo que impide una intervención y seguimiento adecuado para aquellos pacientes que podrían ser abordados desde un mayor umbral de objetivos terapéuticos. Todo parece indicar que los programas con mayores prestaciones y apoyos psico-sociales están en condiciones de ofrecer los mejores resultados (Brugal y Puigdollers, 1999; Mino et al., 1998; Soriano, 2001; Soriano, 1999). En la práctica y existiendo una fuerte demanda de PMM por parte de los usuarios (lista de espera incluida) se prima la implementación de PMM destinados a drogodependientes de bajo umbral de objetivos terapéuticos, potenciando la vertiente bio-médica en detrimento de la psico-social. En aras de la «dispensación radial» (acercar la toma de MTD a un punto más próximo al lugar de residencia del usuario) se ha potenciado la figura del DUE (Diplomado Universitario en Enfermería). Mientras, Trabajadores Sociales y Educadores no se encuentran presentes en la magnitud en que sería deseable y necesario.

Aún contando con que el aumento del acceso a la dispensación de MTD resulta una conquista irrenunciable y que sin duda supone una válvula de contención de la situación, ello no debería acallar la conciencia de quienes saben que esto no supone ni mucho menos un remedio sostenible. Al fin y al cabo se trata de una población politoxicómana. Los PMM abordan directamente la dependencia a heroína pero si no se interviene en las dependencias y consumos paralelos se deja la puerta abierta a varios efectos perversos e indeseables (George, E. y Woody, M.D., 1999). Por ejemplo, algunos usuarios con una fuerte «dependencia psicológica a la vía de consumo» intravenosa pasan a utilizar la cocaína inyectada, generando una conducta más compulsiva y de peor pronóstico. Abundan también los casos en que el usuario acaba generando un abuso o una dependencia a alcohol o benzodiacepinas que se procura, entre otros motivos, con la intención de sentir el «flash» que la MTD no le da. La ratio de profesionales/pacientes en los actuales programas no es suficiente para abordar integralmente la realidad de policonsumo y polidependencias con la que nos encontramos. En algunos recursos, una parte importante de la población en tratamiento pasa 
meses sin acudir a visitas de seguimiento, algo que tiende a achacarse al perfil de la población. Por la orientación «paliativa» de ciertas intervenciones, la permanencia del sujeto en el programa con asistencia a un número muy limitado de visitas suele asumirse como un mal menor, preferible a perder todo contacto con él.

El proceso de admisión es probablemente la etapa más importante de un programa de mantenimiento con metadona. Para los adictos que acuden por primera vez constituye el inicio de la transición de "consumidor de la calle" a "usuario de un centro asistencial". Adherirse al sistema terapéutico, sus servicios, reglas etc. supone un cambio cualitativo dentro de su proceso. Lo que ocurra en esta fase resultará determinante en su actitud, autoestima, interés y motivación a lo largo del tratamiento, por lo que esta experiencia debería ser positiva para el usuario. Una valoración y diagnóstico personalizado debe considerar como aspectos relevantes las principales necesidades «sentidas» por el recién llegado, facilitando así un establecimiento más favorable de las bases de la intervención clínica.

Los Programas paliativos tienen como «única función frenar el deterioro que provoca el consumo de sustancias, ya sea por la imposibilidad de cambio de los individuos o por la presencia de enfermedades en fase avanzada que hagan inviable ningún cambio». Desde otro ángulo, los Programas orientados al cambio acometen como primera intención la contención del daño, pero prevén una posibilidad de cambio a medio plazo, y tras la estabilización de los individuos no descartan avanzar hacia programas orientados a la abstinencia (PND, 1998). Lógicamente, optimizar la potencialidad de cambio de los pacientes solo es compatible con una política que garantice prestaciones integrales más allá de la dispensación de la sustancia.

Si bien no se dispone de predictores fiables que indiquen al inicio de un programa cómo va a ser la evolución de un usuario, sí que se conoce que una estancia prolongada en «mantenimiento» se relaciona con menor riesgo de recaída y mejor evolución posterior. Si a esto unimos la despreciable toxicidad del fármaco, la consideración de cronicidad para el proceso adictivo padecido por muchos pacientes y su utilidad terapéutica para estabilizar determinados trastornos psiquiátricos, no es de extrañar que cada vez se plantee con menores reservas el mantenimiento a largo plazo o permanente en metadona como una alternativa posible y deseable en determinados casos.

En realidad, la toma diaria del fármaco presenta ciertas facilidades a pesar de que se trata de una sustancia cuyo uso se encuentra escrupulosamente regulado en la legislación vigente. De hecho, un paciente o sus familiares pueden ser autorizados según criterio del equipo tera- 
péutico para retirar cada varios días botes de medicación. Esta práctica conocida como «take home» implica responsabilizarse de custodiar la medicación y permite tomarla en el propio domicilio. En ese contexto, y para los pacientes incluidos en programas de alto umbral de objetivos terapéuticos, el seguimiento farmacológico del tratamiento resulta relativamente cómodo si se compara con el de ciertos enfermos crónicos, siendo menos agresivo que la inyección de insulina en el caso de los diabéticos, o la hemodiálisis utilizada para tratar la disfunción renal. Sin duda, la presentación como fluido para su ingestión oral supone una gran ventaja. Incluso el paciente puede desplazarse a otra ciudad o país (por vacaciones, por motivos laborales, etc.) coordinando anticipadamente con su centro prescriptor la retirada provisional de medicación en otro punto de dispensación.

Sin embargo, todavía hoy existen agujeros negros donde el paciente sólo puede encontrar trabas y dificultades. En la práctica, participar en un P.M.M. suele ser considerado un motivo de exclusión para acceder a una casa de acogida de enfermos de SIDA, un albergue de transeúntes o una residencia materno-infantil para mujeres en situación de riesgo. Desde una óptica más aperturista, la prescripción de MTD a pacientes susceptibles de alcanzar altos objetivos terapéuticos puede ser un apoyo más dentro de otros recursos, como los centros de día o las Unidades de Deshabituación Residencial. La evidencia clínica sugiere que existen sectores entre los actuales usuarios de Comunidades Terapéuticas profesionales y de tratamientos con metadona que pueden requerir de la integración de ambos servicios y beneficiarse de ellos (Llorente y Fernández, 1999). El fármaco tiene muchas posibilidades y su uso no debería postergarse casi exclusivamente a población considerada como «residual» o a los programas de «bajo umbral de objetivos».

\subsection{Programas de intercambio de jeringuillas}

La introducción de los PIJ ha conseguido la estabilización de la prevalencia del VIH y otras infecciones de transmisión sanguínea, como la Hepatitis B y C, entre los UDIs. El Reino Unido, Holanda y Suiza son los máximos representantes de la puesta en marcha de estrategias y programas para favorecer el acercamiento a los usuarios de drogas inyectables, entre los que se encuentran estas intervenciones. Los PIJ, básicamente, son programas con un objetivo principal, común a otras acciones de reducción de daños: prevenir la infección por VIH y otras enfermedades infecciosas, mediante la dispensación de material estéril para el uso de drogas por vía parenteral. Entre los objetivos específicos que persiguen destacamos: 
- Disminuir las prácticas de inyección de drogas que conllevan riesgos, como el uso compartido de jeringuillas, dar y/o recibir drogas previamente diluidas en una jeringuilla usada, y compartir otros materiales relacionados con la preparación y administración de la dilución de drogas (recipientes para disolver la sustancia, algodones, agua, etc.).

- Disminuir las prácticas sexuales de riesgo.

- Mejorar el acceso de los inyectores de drogas a los recursos sanitarios y sociales generales (como centros de Atención Primaria, servicios sociales generales), y específicos (como consultas hospitalarias para control y tratamiento de infecciones y centros de tratamiento en caso de ser requeridos).

- Aumentar el porcentaje de inyectores que se han realizado el test anti-VIH y pruebas serológicas frente a los virus de la hepatitis (B y C).

- Mantener la vigilancia epidemiológica mediante la recogida sistemática de datos para el estudio de la población que acude a los programas y más específicamente de las conductas de riesgo para la transmisión de VIH.

- Monitorizar las modificaciones de los patrones de consumo de drogas entre la población atendida. Parece que el consumo de cocaína y crack se asocian a un incremento de las prácticas de riesgo para la transmisión de VIH.

- Asegurar a medio y a largo plazo, la asimilación del cambio de hábitos y prácticas de riesgo.

- Contribuir a disminuir el número de jeringuillas usadas abandonadas.

\section{Actividades de los Programas de Intercambio de Jeringuillas}

- Distribución de material de prevención: jeringuillas, agua bidestilada, alcohol, ácido cítrico, papel de plata, preservativos, etc.

- Recogida de jeringuillas usadas en contenedores de residuos especiales (según la normativa para la eliminación de residuos y materiales contaminantes).

- Educación para la salud.

- Instrucción sobre inyección de menos riesgo.

- Instrucción sobre sexo más seguro.

- Derivación a otros recursos asistenciales.

- Elaboración y divulgación de material informativo sobre prevención de riesgos.

Se pueden emplear dos tipos de estrategias:

A. En la que el usuario ha de desplazarse al centro donde se realiza el intercambio, utilizando recursos socio-sanitarios ya existentes 
o un lugar donde se ubica una máquina dispensadora de jeringuillas. Este tipo de intervención requiere una persistente actividad de sensibilización entre los usuarios para motivar que acudan a participar. Algunos PIJ se realizan desde farmacias que colaboran de un modo protocolarizado en la actividad.

B. En la que se utiliza una Unidad Móvil (caravana, furgoneta...) que se desplaza a los lugares de venta/consumo tratando de facilitar al máximo la accesibilidad al programa de intercambio. Normalmente se concretan horarios y lugares estables para organizar la actividad coincidiendo con los usos habituales de esta población.

Ambas estrategias han de ser complementarias, es decir, hay que facilitar el acceso del usuario al material estéril, completando una oferta de atención con puntos fijos de intercambio (centros o locales), unidades móviles (acercamiento) y máquinas intercambiadoras para asegurar así la disponibilidad del material durante las 24 horas del día, todos los días del año. La eficacia de los PIJ está suficientemente consensuada, tanto para disminuir la propagación del VIH (con estimaciones de una reducción de nuevos casos de hasta un $33 \%$ en los usuarios del PIJ que se ha desarrollado en New Haven, Connecticut, EEUU), como por la importante tasa de retorno de jeringuillas suministradas (superior al 70\%).

Cabe recordar, que aunque nos hemos venido refiriendo mayormente a personas con trastorno por dependencia a opiáceos (PTDO), las referencias UDVP (usuarios de drogas vía parenteral) y UDIs (usuarios de drogas inyectables) incluyen a los autoinyectores de cocaína, que presentan análogas prácticas de riesgo asociadas a la vía. De hecho, es común el patrón de consumo que combina el consumo de heroína fumada/inhalada y cocaína inyectada. Este patrón puede estar relacionado, entre otros aspectos, con el tipo y pureza de las sustancias que se encuentran al alcance del usuario.

\subsection{Centros de encuentro y acogida}

En el año 1990, la Comisión mixta Congreso-Senado para el estudio del problema de las Drogas, elaboró una propuesta de medidas, entre las que se encontraba la de "habilitar, en las grandes ciudades, centros abiertos 24 horas para situaciones que requieran una atención inmediata". La Comisión definía estos centros como "Centros de Emergencia Social". Se trata de un recurso de atención y cuidados mínimos, que se apoya en una estructura asistencial diseñada y desarrollada específicamente para población usuaria de drogas inyectables. Este tipo de 
intervención está dirigida a los usuarios de drogas más deteriorados desde el punto de vista socio-sanitario que no acceden a las redes asistenciales normalizadas. En algunos de ellos coinciden varias circunstancias motivo o efecto de marginación, como vivir en la calle, presencia de trastornos mentales, ser inmigrante en situación irregular, ex-reclusos ...

A los centros de acogida se accede directamente, sin derivación previa. En ocasiones se trata de usuarios de otro tipo de recursos, como albergues, comedores sociales, etc. La ubicación de estos centros puede variar en función de las necesidades de cada ciudad, pero suelen preferirse algunas de las siguientes alternativas:

- Zonas céntricas degradadas (como pueden ser algunos barrios antiguos).

- Zonas de especial conflictividad (barrios donde se encuentra población inmigrante en situaciones de grave precariedad, prostitución, áreas portuarias, etc.)

- Espacios abiertos frecuentados por población marginal (solares deshabitados, encrucijadas de carreteras, etc.).

Por regla general se considera que la ubicación ha de ser lo más cercana posible a los escenarios cotidianos del UDI.

Actividades de los centros de encuentro y acogida:

- Servicio de acogida e información: en general se informa de lugares para dormir, comer, recibir atención sanitaria o tratar su adicción, etc.

- Servicio de intercambio de material o PIJ: jeringuillas, preservativos, etc.

- Servicio de estancia y descanso (también se les llama sala de calor y café), donde prima el trato personalizado entre el usuario y el educador, en un clima tranquilo y confortable; algunos centros disponen de salas con camas para dormir unas horas.

- Servicios de higiene: Duchas, cambio de ropa, lavadora, etc.

- Servicio sanitario de urgencia y medicina preventiva: curas, diagnóstico precoz de embarazo, vacunaciones, etc.

- Servicio de educación para la salud: consejo, charlas, talleres, etc.

- Servicio de valoración socio-sanitaria: atención, información, orientación y asesoramiento básico.

- Servicio de coordinación y contacto con otros recursos: gestión de derivación y canalización de atenciones varias.

El talante del equipo profesional en estos centros debe contemplar buenas dosis de flexibilidad, baja exigencia en las normas, respeto y claridad en los límites. 


\subsection{Salas de venopunción higiénica}

Estos dispositivos intentan abrirse camino en nuestro país con una denominación que, como mínimo, se puede catalogar de desafortunada: "Narcosalas". La palabra narcótico viene del griego "narcosis" que quiere decir sueño profundo, sin retorno. Siempre que se utiliza la palabra "narcótico" en el lenguaje actual, está ligada a algo fatal y/o delictivo, ..., brigada de narcóticos, narcotráfico, narcotraficante, etc.

Son salas donde el usuario de drogas inyectables más desestructurado socialmente, que vive y que consume habitualmente en la calle, puede consumir sustancias inyectadas en condiciones sanitarias más dignas. Se les dota de material estéril para el uso parenteral (jeringuilla, agua destilada, alcohol, ácido cítrico, etc.), y están bajo la tutela de médicos, DUEs y trabajadores sociales, etc. Además las instalaciones están equipadas con material de urgencias y reanimación.

Las unidades de venopunción existen en Holanda y Suiza desde hace años. Tienen como objetivo principal acercar a la red asistencial social y sanitaria a los UDIs sin hogar y con numerosos intentos fracasados de integrarse en distintos planes terapéuticos. En España, la primera sala en abrir sus puertas fue la de "La Barranquilla", en Madrid, a principios de 2000 , y su apertura fue objeto de innumerables debates desde distintas esferas de la vida social y política.

Argumentos a favor: Pueden ser el único punto de contacto con la red de recursos socio-sanitarios para un grupo de usuarios de drogas con graves deterioros. Para éstos, la sala de inyección es casi la única posibilidad de consumir en unas condiciones de "menor riesgo".

Argumentos en contra: El usuario aporta la sustancia que se va a inyectar, en la actualidad las drogas "ilegales" son preparadas en laboratorios clandestinos y adquiridas en el mercado negro, por lo tanto no existe ningún control sanitario sobre ellas. El médico o enfermera, en ningún momento saben la cantidad de pureza o la sustancia «de corte» que se está inyectando el usuario, por lo tanto es difícil prevenir las reacciones adversas, situaciones de sobredosis, anafilaxis, etc.

Tal y como ocurre en Holanda, las salas pueden disponer de un servicio de análisis inmediato y voluntario de la composición de las sustancias que aportan los usuarios.

\subsection{Programas de dispensación controlada de heroína}

La utilización de la heroína en programas de mantenimiento para adictos a opiáceos, ha sido objeto de investigaciones de experiencias 
piloto en distintos países de Europa, Inglaterra-Liverpool (1968), Holanda-Amsterdam (1979), Suiza-Ginebra (1994), Bélgica (1995), Australia (1995). Desde los años setenta se propone que la administración de heroína prescrita y controlada por un médico puede producir índices de retención superiores a los obtenidos por los PMM. Si esta idea hubiera tardado menos años en calar se habría contribuido generosamente a controlar la transmisión de enfermedades derivadas de la forma de consumo, entre ellas la infección por VIH/SIDA.

En la Declaración de Helsinki, en la que se formalizan los principios para una buena práctica médica, se contempla el hecho de que cuando no existe un tratamiento adecuado, el paciente recibirá aquél que maximice sus posibilidades de mantener la vida y de mejorar la calidad de ésta. Sabemos, por la experiencia de trabajo en los PMM, que aproximadamente un $30 \%$ de los usuarios de estos programas abandonan el mismo.

El análisis de las experiencias suiza y británica pone en evidencia que el desarrollo de los tratamientos con heroína se ha realizado en armonía con su especificidad social, política, histórica, científica y económica y en el marco de una serie de medidas globales destinadas a ofrecer una respuesta coherente, diversificada y adaptada a un fenómeno complejo y multidisciplinar, como son los trastornos relacionados con el uso de sustancias. La experiencia del estudio australiano confirma la necesidad de abordar progresivamente las etapas, desarrollando la "oferta de heroína" como un elemento más dentro de la gama de respuestas. En el Estado español, sólo dos Comunidades Autónomas (Andalucía y Cataluña) han puesto en marcha iniciativas o comisiones para la valoración del desarrollo de programas de tratamiento con heroína.

\section{CONCLUSIONES}

- La infección por VIH/SIDA representa hoy por hoy el fenómeno que mayores transformaciones ha procurado en el ámbito de abordaje de las conductas adictivas asociadas al consumo de drogas vía parenteral.

- Las políticas de reducción de daños constituyen un vector de intervención en continua expansión y evolución, suponen un avance técnico e ideológico irrenunciable, y gozan progresivamente de mayor consenso y credibilidad científica y social.

- Las políticas de reducción de daños deben contemplar nuevas estrategias más integrales e interdisciplinares, la vertebración del eje 
psico-social requiere un impulso decisivo por parte de Administraciones, instituciones y profesionales.

- El escenario en el que se plantean buena parte de los programas de mantenimiento de metadona en España hoy está más cerca de «reducir los daños a la colectividad» que de procurar una atención personalizada y de suficiente calidad a sus usuarios. No existe infraestructura para optimizar la potencialidad terapéutica de cada paciente en cada momento.

- La población cronificada en el consumo de drogas inyectables que presenta peor pronóstico requiere nuevas respuestas por parte del circuito de recursos. El diseño de nuevas alternativas de convivencia y de espacios para la atención de las necesidades básicas en los procesos terminales debe promover una existencia más digna y más humana.

\section{BIBLIOGRAFÍA}

ARDIZABALAGA, I; SERRANO, M.; (1995): Tratamiento de Mantenimiento con Metadona: "Una intervención multidisciplinaria y comunitaria". III Jornada de Psicología en Navarra. Conferencias y Comunicaciones. Colegio Oficial de Psicólogos de Navarra.

ASTASIO, M.; (1992): Programas de mantenimiento con metadona; En FERNÁNDEZ, A. et al.: Adicción a la heroina. IDEPSA. Madrid.

BALL J.C.; ROSS, A. (1991): The effectiveness of Methadone Maintenance Treatment. Patients, Programs Services, and Outcome. New York, SpringerVerlag.

BROONER, R.K.; GREENFIELD, L.; XCHMIDT, C.W. (1993): Antisocial personality disorders and HIV infection among intravenous drug abusers. Arch. Gen. Psychiatry. 54: 71-80.

CANO, L. y MAYOR, L. (1998): La intervención psicológica en el marco de las Drogodependencias. Informació Psicològica. Col-legi Oficial de Psicòlegs del País Valencià. 1998. n 66. pag. 10-18. Valencia.

CATAÑEDA, M. (1992): Conceptos básicos en adicción a la heroína. En FERNÁNDEZ, A. et al.: Adicción a la heroina. IDEPSA. Madrid.

Decreto 47/1998, de 5 de abril, del Gobierno Valenciano, sobre Registro y Acreditación de Centros y Servicios de Atención y Prevención de las Drogodependencias y otros Trastornos Adictivos en la Comunidad Valenciana (DOGV n ${ }^{\circ}$ 3.235, de 05-05-98).

E.T. U.C.A. CRUZ ROJA VALENCIA (1998): Estudio de una muestra de adictos a opiáceos incluidos en un Programa de Mantenimiento con Metadona: 
perfil psicológico, social y patología orgánica. Libro de Comunicaciones del V Encuentro Nacional sobre Drogodependencias y su Enfoque Comunitario. Dip. de Cádiz, Junta de Andalucía, P.N.D., F.A.D.; Chiclana de la Frontera (Cádiz).

COLEGIO OFICIAL DE PSICÓLOGOS. DELEGACIÓN DE MADRID (1996): Intervención en Drogodependencias: Áreas y Técnicas. Madrid.

DE ANDRÉS, M. (1995): Reducción de riesgos. Jano (monográfico). Drogodependencias diez años después del SIDA. $\mathrm{n}^{\circ} 1.140$.

DEL RÍO, Ma ${ }^{\mathrm{a}}$. et al. (1999): Guía de INTERNET sobre alcohol y drogas de abuso. Du Pont Pharma. Valladolid.

DEL RÍO, M. (1994): Programas de Mantenimiento con Heroína. I Conferencia Nacional sobre el SIDA, Madrid, Ministerio de Sanidad y Justicia e Interior. Madrid.

DES JARLAIS, D.J. (1992): The first and second decades of AIDS among injecting drugs users. British Journal of Addiction.

ESTEVE, M.L. et al. (1998): Áreas y técnicas en el proceso de atención psicológica en los Programas de Mantenimiento con Metadona. Intervención Psicosocial, 1.998, vol. 7, $\mathrm{n}^{\circ} 2$, pags. 217-227. Valencia.

G.V.; (1999): Tú puedes prevenir el SIDA. Dirección General de Salud Pública. Conselleria de Sanitat. Valencia.

GEORGE, E.; WOODY, M.D. (1999): Injected cocaine and other substance use by patiens in methadone maintenance treatment. Libro de Ponencias $V$ Conferencia Nacional sobre SIDA y Drogas. Ministerio de Sanidad y Consumo - Ministerio del Interior. Madrid.

GINER, F. (1999): ¿Tratamientos con heroína?. CREFAT. nº 11. Cruz Roja Española. Madrid.

GRUPO SIDA. COP- MADRID (1996): La importancia del Psicólogo en los P.M.M. III Encuentro de Psicología en Drogodependencias. COP - Madrid.

GUTIÉRREZ, E. et al. (1998): Trastornos de personalidad en adictos a opiáceos en tratamiento con agonistas vs antagonistas. ADICCIONES, 98 vol.10, $n^{\circ} 2$.

HERNÁNDEZ, J.J.; GINER, F. (1999): Los programas de mantenimiento con metadona. Una aproximación a sus aspectos jurídicos y clínicos. SEISIDA. vol. 10. n'. 3. pag. 117.

INSÚA, P. et al. (1999): Manual de Educación Sanitaria: recursos para disenar Talleres de prevención con usuarios de drogas. Programa de Formación para la prevención de los problemas de salud asociados al consumo de drogas. PND - PNS - Universidad del País Vasco.

JOE, G.W.; SIMPSON, D.D.; HUBBAR, R.L. (1991): Treatment predictors of 
tenure in methadone maintenance. Journal of Substance Abuse, 3: 73-84.

KREEK, M.J. (1983): Health consequences associated with the use of methadone. In: CCOER, J.R.; ALTMAN, F.; BROWN, B.S.; CZECHOWICZ, D., eds.: Research on the Treatment of Narcotic Addiction; State of the Art. National Institute on Drug Abuse Research.

LLORENTE, J.M.; FERNÁNDEZ, C. (1999): La comunidad terapéutica profesional en el abordaje de pacientes en tratamiento de metadona. Trastornos adictivos. Vol. 1 - n 3-4 pag. 251-258. Madrid.

MAGRANE, M.; VELILLA, A. (1996): La intervención del Trabajador Social en los programas de mantenimiento con metadona para personas drogodependientes. VI Congreso Estatal de Diplomados en Trabajo Social y Asistentes Sociales. Sevilla.

MINO, A. et al. (1998): Análisis de un programa público de metadona de dos años. Libro de Ponencias del V Encuentro Nacional sobre Drogodependencias y su Enfoque Comunitario. Dip. de Cádiz, Junta de Andalucía, P.N.D., F.A.D.; Chiclana de la Frontera (Cádiz).

NEWCOMBE (1989): Working Party on Harm Minimization . Evaluating Drugs and AIDS Prevention Policies. Institute for the Study of Drug Dependence. London.

NIDA; (1999): INFOFAX. Heroína National Institute on Drug Abuse. National Institutes of Health. http://www.nida.nih.gov/

NIEVA, P.; BAULENAS, G.; BORRAS, T. (1995): Centros de Encuentro y Acogida, documento de referencia. IPSS; GRUP IGIA; P.N.D. Barcelona.

O'HARE, P.A.; NEWCOMBE, R. et al. (1995): La reducción de daños relacionados con las drogas. Ed. Grup Igia. Barcelona. (Orig. 1992).

Plan Nacional sobre el S!DA (1996): Guía para la puesta en marcha de programas de intercambio de jeringuillas. Dirección General de Salud Pública. Ministerio de Sanidad y Consumo. Madrid.

P.N.D. (1998): Servicios Sociales y Drogodependencias: Actuar es posible. Delegación del Gobierno para el Plan Nacional sobre Drogas - Ministerio del Interior. Madrid.

P.N.D. (1999): Observatorio Español Sobre Drogas - Informe n ${ }^{\circ} 2$. Delegación del Gobierno para el Plan Nacional sobre Drogas - Ministerio del Interior. Madrid.

P.N.D. (2000): Observatorio Español Sobre Drogas. Delegación del Gobierno para el Plan Nacional sobre Drogas - Ministerio del Interior. Madrid.

SANCHÍS, M.; MARTÍN, E. (1997): Alcohol y drogas: depende de todos. Conselleria de Benestar Social. Generalitat Valenciana. Valencia.

SCHERING-PLOUGH, S.A. (1998): Hablemos de La Hepatitis Vírica. ScheringPlough, S.A. BIOTECH. Ediciones ACV. Barcelona. 
SORIANO, R. (2001): Reducción de daños entre usuarios de drogas inyectables: un enfoque social. Valencia (próxima publicación).

SORIANO, R. (1999): Voluntariado como apoyo en un Programa de Mantenimiento con Metadona. R.T.S. Revista de Treball Social. No 155; pag. 87-99. Barcelona.

SORIANO, R. (1998): Intervención Social en VIH/SIDA. Col. Hvmanitas 2.000. Serie Intervención Social. Ed. LUMEN-HVMANITAS. Buenos Aires.

ZUNZUNEGUI PASTOR, M.V.(1998): Estudio comparativo aleatorizado abierto entre heroína intravenosa y metadona oral durante un año en el mantenimiento de pacientes con adicción a opiáceos que han fracasado en tratamientos actualmente disponibles: Programa experimental de prescripción de estupefacientes en Andalucía. (PEPSA). EASP. 